\title{
Transfer and expression of the rabbit defensin NP-1 gene in lettuce (Lactuca sativa)
}

\author{
D. Song, X. Xiong, W.F. Tu, W. Yao, H.W. Liang, F.J. Chen and Z.Q. He \\ Biotechnology Research Center of China Three Gorges University, \\ Yichang Hubei, China \\ Corresponding author: Z.Q. He \\ E-mail: zhq_he@163.com
}

Genet. Mol. Res. 16 (1): gmr16019333

Received September 21, 2016

Accepted September 21, 2016

Published January 23, 2017

DOI http://dx.doi.org/10.4238/gmr16019333

Copyright (C) 2017 The Authors. This is an open-access article distributed under the terms of the Creative Commons Attribution ShareAlike (CC BY-SA) 4.0 License.

\begin{abstract}
Lettuce (Lactuca sativa L.) is an annual plant of the daisy family, Asteraceae, with high food and medicinal value. However, the crop is susceptible to several viruses that are transmitted by aphids and is highly vulnerable to post-harvest diseases, as well as insect and mammal pests and fungal and bacterial diseases. Here, the rabbit defensin gene $N P-1$ was transferred into lettuce by Agrobacteriummediated transformation to obtain a broad-spectrum disease-resistant lettuce. Transgenic lettuce plants were selected and regenerated on selective media. The presence of the NP-1 gene in these plants was confirmed by western blot analyses. Resistance tests revealed native defensin NP-1 expression conferred partial resistance to Bacillus subtilis and Pseudomonas aeruginosa, which suggests new possibilities for lettuce disease resistance.
\end{abstract}

Key words: Lettuce; Transgenic plants; Rabbit defensin gene NP-1

Genetics and Molecular Research 16 (1): gmr16019333 


\section{INTRODUCTION}

Lettuce (Lactuca sativa L.) is a globally important leafy vegetable that is widely grown and easily cultivated, although it requires relatively low temperatures. Lettuce is low in calories and rich in lactucin and mannitol (Song et al., 2014). Lactucin is an ingredient of lactucarium that is found in some varieties of lettuce, and has been shown to have analgesic and sedative properties (Wesołowska et al., 2006). Mannitol is used in osmotherapy to reduce acutely raised intracranial and intraocular pressure, and also plays a key role in the treatment of brain edema and glaucoma (Rabinstein, 2006). Currently, the quality and yield of lettuce is severely constrained by plant diseases such as Lactuca sativa Sclerotinia and Pseudoperonospora cubensis. Lactuca sativa Sclerotinia is widespread in lettuce plantations globally, and causes considerable damage to the basal part of stems and leaves (Waipara, 2006; Chitrampalam et al., 2010).

There has been considerable research, locally and globally, to improve the disease resistance of lettuce. In addition to traditional breeding methods, such as disease resistant plant seed selection, research on cultivating resistant transgenic plants using molecular methods has recently increased. Zhang et al. (2010) transferred the MI-1 gene into lettuce, and the T1 generation transgenic plants showed resistance to root-knot nematodes. Dias et al. (2006) transferred the decarboxylase gene (oxdc) into lettuce, and RT-PCR analysis carried out with Sclerotinia-resistant lines indicated the expression of oxdc gene transcripts. Yoichi et al. (2006) transferred the $L B V a V C P$ gene into lettuce and found that this line had resistance to both the big-vein associated virus and Mirafiori lettuce virus. Subsequently, the MiLVCP gene transferred into lettuce with resistance to big-vein disease was also obtained, and this was the first report of an inserted nucleotide sequence derived from the genus Ophiovirus to create virus-resistant plants (Yoichi et al., 2009). Therefore, this research indicated that it was possible to use transgenic lettuce as a resistant cultivar or breeding source.

Rabbit defensin (NP-1) has significant inhibiting or killing effects on pathogenic microorganisms such as Gram-positive and -negative bacteria, fungi, viruses, and even some malignant cells (such as tumor cells and HIV), which was determined by antibacterial tests in vitro (Zhou et al., 2011). As a new broad antibacterial spectrum defensin, it possesses far-reaching implications in plant transformation. The mechanism of rabbit defensin (NP-1) determined that it was difficult to target microorganisms to yield resistant mutations. Recently, rabbit defensin (NP-1) has been transformed into some plants and expressed via genetic engineering (such as the pollen tube pathway and Agrobacterium mediation), which plays an important role in the genetic engineering of anti-disease plants and plant species improvements (Zhou et al., 2011).

The aim of the present study was to successfully apply an Agrobacterium-mediated transformation strategy to obtain transgenic lettuce that could stably express NP-1. Simultaneously, we established effective test methods, which accurately and stably determined the biological activity of the transformed plants, and laid the foundation for cultivating transgenic lettuce with broad-spectrum disease resistance. The NP-1 gene was applied in two sequential transformation steps to develop transgenic lettuce.

\section{MATERIAL AND METHODS}

\section{Bacterial strains and plasmids}

The A.tumefaciens bacterial strain harboring the plasmid pBinU-Omega-HisNP1

Genetics and Molecular Research 16 (1): gmr16019333 
(Figure 1) was used for transformation of lettuce. The binary plasmid, pBinU-Omega-HisNP1, gifted by the Chinese Academy of Science Institute of Genetics and Developmental Biology, was constructed by inserting a $130 \mathrm{bp}$ fragment harboring the $N P-1$ gene under the Ubiquitin promoter and NOS terminator. The NP-1 gene upstream of the His-NP1 sequence contained six His-tags, and a small $2.3-\mathrm{kb}$ fragment that could be recovered by HindIII and SacI double digestion from the plasmid. The transconjugants were selected on LB medium with $50 \mathrm{mg} \mathrm{L}^{-1}$ kanamycin and $50 \mathrm{mg}$ $\mathrm{L}^{-1}$ rifampicin, and the presence of plasmids was confirmed by PCR analysis.

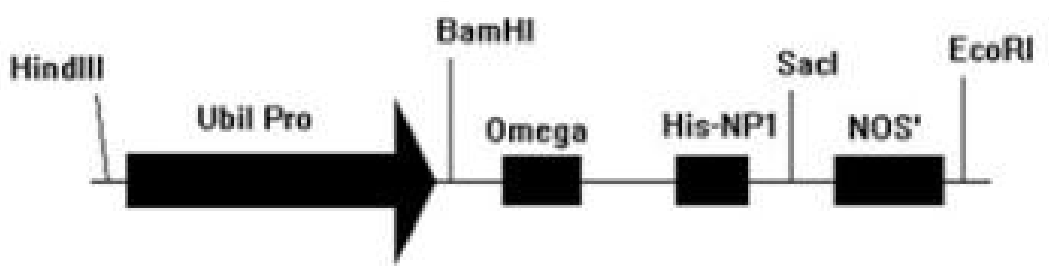

Figure 1. The T-DNA region of the plasmid, pBinU-Omega-HisNP1, used for lettuce transformation. Nos, polyadenylation and termination signals; His-NP1, rabbit defensinNP-1 coding sequence; Ubi Pro, Ubiquitin promoter.

\section{Plant material and transformation}

Mature seeds of the Zhengyuan Italy lettuce, purchased from the Vegetable and Seed Center of Yichang were used to produce cotyledons, which were used for shoot regeneration on the shoot induction medium [MS salts (Murashige and Skoog, 1962), $0.5 \mathrm{mg} / \mathrm{L}$ 6-Benzylamino Adenine (6-BA), $0.3 \mathrm{mg} / \mathrm{L}$ Naphthylacetic Acid (NAA), $30 \mathrm{~g} / \mathrm{L}$ sucrose, and $8 \mathrm{~g} / \mathrm{L}$ agar, $\mathrm{pH}$ 5.8]. Agrobacterium was grown on LB medium at $28^{\circ} \mathrm{C}$ in a shaker $(180 \mathrm{rpm})$ until an optical density of $0.4\left(\mathrm{OD}_{600}\right)$ was reached. Bacterial cells were pelleted by centrifugation at $10,000 \mathrm{~g}$ for $10 \mathrm{~min}$ at $28^{\circ} \mathrm{C}$ and re-suspended in an equal volume of MS medium supplemented with $100 \mu \mathrm{M}$ acetosyringone (AS). The cotyledons were excised and pre-incubated on the medium for 2 days and then infected by swirling in the Agrobacterium culture for $10 \mathrm{~min}$. The infected cotyledons were co-cultivated on the co-cultivation medium (MS salts, $0.5 \mathrm{mg} / \mathrm{L}$ 6-BA, 0.3 $\mathrm{mg} / \mathrm{L} \mathrm{NAA}, 30 \mathrm{~g} / \mathrm{L}$ sucrose and $8 \mathrm{~g} / \mathrm{L}$ agar, $100 \mu \mathrm{M} \mathrm{AS}, \mathrm{pH}$ 5.6). After 2-3 days, the cotyledons were placed on the selection medium supplemented with $75 \mathrm{mg} / \mathrm{L}$ kanamycin (Kan) and 500 $\mathrm{mg} / \mathrm{L}$ carbenicillin (Carb) to prevent Agrobacterium growing excessively. When adventitious buds grew to $1-2 \mathrm{~cm}$, they were transplanted to the $1 / 2 \mathrm{MS}$ medium with $0.1 \mathrm{mg} / \mathrm{L}$ Indoleacetic Acid (IAA). Finally, the transgenic plants were acclimatized and grown in a greenhouse.

\section{PCR analysis of the transgenic lettuce plants}

The genomic DNA of transgenic and wild-type lettuce were taken from leaves and extracted using the CTAB method. PCR was performed using primer pairs specific for the coding sequence of NP-1 (Forward: 5'-GCCATCATCATATGGTTGTTTGTGCA-3', Reverse: 5'-GCGAGCTCTTAACGACGACAACAAAGTGG-3'). The PCR cycle conditions were: $94^{\circ} \mathrm{C}$ for $30 \mathrm{~s}, 55^{\circ} \mathrm{C}$ for $30 \mathrm{~s}, 72^{\circ} \mathrm{C}$ for $30 \mathrm{~s}$ for 35 cycles followed by an initial denaturation at $94^{\circ} \mathrm{C}$ for $3 \mathrm{~min}$, and a final extension cycle at $72^{\circ} \mathrm{C}$ for $10 \mathrm{~min}$. The PCR products were separated on $2 \%(\mathrm{w} / \mathrm{v})$ agarose gel to show whether the $130 \mathrm{bp}$ specific bands existed. 


\section{Southern blot analysis}

Plant DNA from control and transgenic lettuce plants were digested with restriction enzymes (HindIII and SacI, the resulting fragments were electrophoresed in $0.8 \%$ agarose gel (Agarose II, Sigma, USA) and detected by ethidium bromide staining. After depurination and denaturation, DNA was transferred to a nylon membrane (Boehringer Mannheim). The DNA probe was labeled with Digoxigenin (DIG) (Boehringer Mannheim, USA). Hybridization was performed at $42^{\circ} \mathrm{C}$ overnight. The Hybond-N+ membrane was washed using $2 \mathrm{X}$ SSC buffer containing $0.1 \%$ SDS for $5 \mathrm{~min}$ (twice) at $25^{\circ} \mathrm{C}$, then washed using $0.5 \mathrm{X} \mathrm{SSC}$ buffer containing $0.1 \%$ SDS for 15 min (twice) at $68^{\circ} \mathrm{C}$. The immunological detection of the DIGlabeled probe was performed using a DIG Wash, Anti digoxigenin-AP conjugate (Roche), and Block Buffer Set (Roche).

\section{Western blot analysis}

The expression of the target gene was detected by western blotting. The total protein from control and transgenic lettuce plants that showed a hybridization signal in the Southern blot was extracted using a Plant Protein Extraction Kit (ComWin, China). The protein samples were separated on a 10\% Sodium Dodecyl Sulfate Polyacrylamide Gel Electrophoresis (SDS-PAGE) gel and electro-transferred onto a Polyvinylidene Fluoride (PVDF) membrane in an electroblotting transfer buffer. The membranes were blocked with 5\% non-fat milk powder in Tris Buffered Saline Tween (TBST) with gentle agitation overnight to prevent non-specific antibody reaction. The membrane was incubated at $25^{\circ} \mathrm{C}$ for $2 \mathrm{~h}$ in a 1:800 dilution of Anti-His Tag Monoclonal Antibody (ComWin, China) in a TBST antibody dilution buffer and washed five to six times with TBST buffer. Then, the membrane was incubated for $2 \mathrm{~h}$ in a 1:50,000 dilution of goat anti-mouse antibody labeled with horseradish peroxidase (Boster, China) in TBST buffer and washed five to six times using TBST buffer. Antibody binding was detected by incubation with an ECL substrate solution, following the manufacturer's instructions. An image analysis of the western blot was conducted using a Kodak Imaging Station (Kodak, USA).

\section{In vitro antimicrobial assay}

The anti-microbial activity of protein from transgenic lettuce extracts was tested using agar plates. Each plate contained four wells; three wells were filled with equal volumes of protein from the transgenic lettuce, and the other one well was filled with the same volume of protein from the wild-type lettuce. Liquid cultures of Bacillus subtilis and Pseudomonas aeruginosa were spread on the agar plates and grown under appropriate conditions. After a period of microbial proliferation, growth inhibition was observed and photographed as the appearance of clear zones.

\section{RESULTS}

\section{Agrobacterium-mediated lettuce transformation}

The seedlings were cut at five days (Figure 2A). After Agrobacterium-mediated transformation, kanamycin-resistant adventitious buds were induced into a clump shoot on the 
selection medium after 3-4 weeks of culture (Figure 2B). The transgenic shoots regenerated, whereas those of the control group was induced into a bud, gradually became brown, and died. After these 1-2 cm long transformed shoots were transferred to $1 / 2 \mathrm{MS}$ with $0.1 \mathrm{mg} / \mathrm{L}$ IAA, complete plantlets were developed (Figure 2C) and rooted (Figure 2D). The transgenic lettuce was transplanted to a greenhouse for acclimation (Figure 2E); however, some abnormal plantlets died during acclimation in the greenhouse.

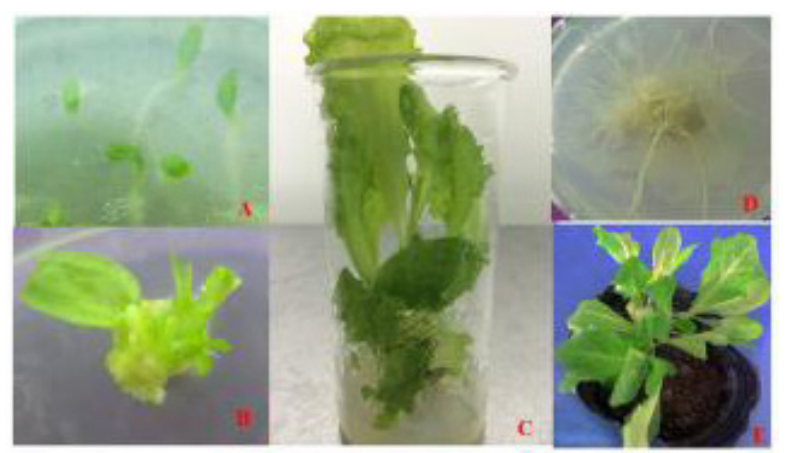

Figure 2. Acquisition of transgenic lettuce plants: A. 5-day-old seedlings; B. adventitious buds; C. complete plantlets; D. rooting of resistant buds; E. transplanted resistant plants.

\section{PCR analyses of regenerated lettuce plants}

Total DNA samples were extracted from the leaves of regenerated lettuce plantlets with kanamycin resistance. The results of the PCR analysis of the transgenic and non-transgenic lettuce DNA samples are shown in Figure 3. DNA samples from the regenerated plants and positive control plasmids showed amplification products with an expected size (130 bp), whereas there was no signal in non-transgenic plant DNA. The PCR experiments initially suggested that the $N P-1$ sequences were presented in the genome of most of the regenerated lettuce plants.

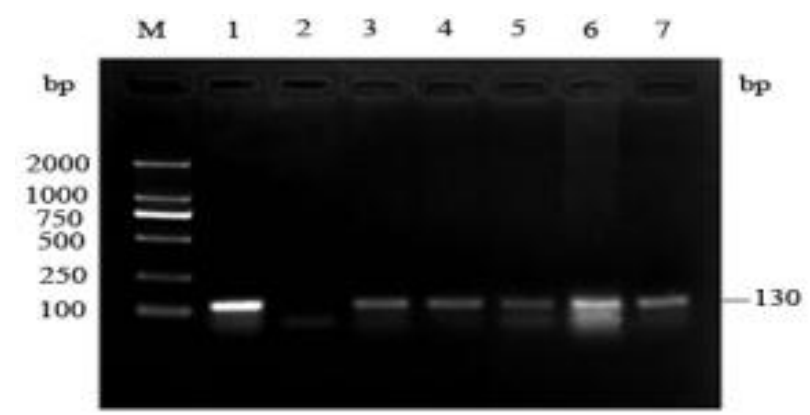

Figure 3. PCR analysis of regenerated lettuce plants: DNA marker (lane $M$ ), positive control plasmid pBinU-OmeHisNP1 (lane 1), and an untransformed plant (lane 2). A 130-bp PCR fragment was found both in the genomic DNA (lanes 3-7) and positive control plasmid.

\section{Southern blot analysis}

The integration of the NP-1 gene into lettuce with amplified PCR target fragments was

Genetics and Molecular Research 16 (1): gmr16019333 
confirmed by Southern blotting. In Southern blot hybridization experiments, DNA samples from the regenerated lettuces hybridized with the probe derived from the $N P-1$ gene (Figure $4 \mathrm{~A}$ ), and the intensities of the hybridization signals differed among the various DNA samples. Therefore, the DNA samples with strong signals were analyzed further. Hybridization signals were observed in the transgenic lettuce lines; one insertion site of the NP-1 gene was detected in these lines, which confirmed that the $N P-1$ gene was transmitted stably to transgenic lettuce (Figure 4B). From the results, it can be seen that different hybridization signals were obtained, even in the same DNA samples.
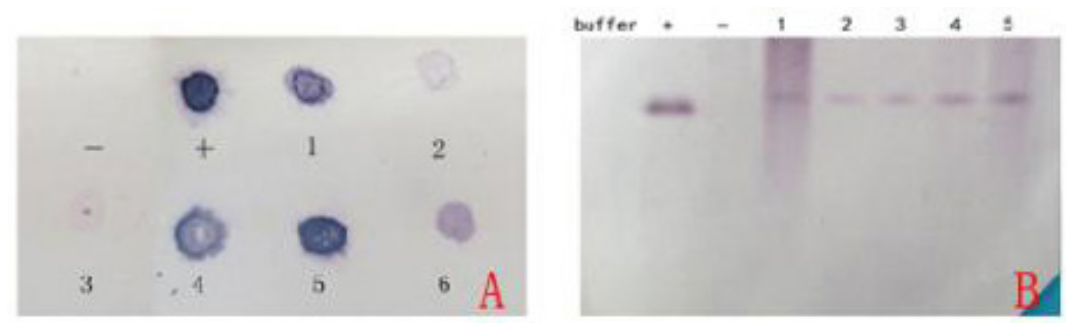

Figure 4. A. Southern blot analysis of genomic DNA from transformed lettuce plants. A. Lane - = negative control, lane $+=$ positive control, lanes $1-6=$ transgenic plants; B. lane $+=$ positive control, lane $-=$ negative control, lanes 1-5 = transgenic plants. Southern blot analysis (B) of plant genomic DNA products from control and transgenic lettuce plants were digested with restriction enzymes (HindIII and SacI).

\section{Western blot analysis}

In the present study, monoclonal antibodies labeled with anti-His were selected as the primary antibodies and goat anti-mouse antibodies labeled with horseradish peroxidase as the second antibodies. The presence of protein crude extracts of transgenic lettuce with Southern blot hybridization signals were detected by western blotting, which showed hybridization signals in the Southern blot. There was no protein signal in wild-type lettuce plants. The size of the target protein monomer was about $3.9 \mathrm{kDa}$. The positive bands appeared in the position of about $40 \mathrm{kDa}$, and lanes 1-6 were also located in the position of about $40 \mathrm{kDa}$ (Figure 5), which demonstrated that the target protein existed in the form of a polymer in a water solution and the target gene was expressed preliminarily in plants.

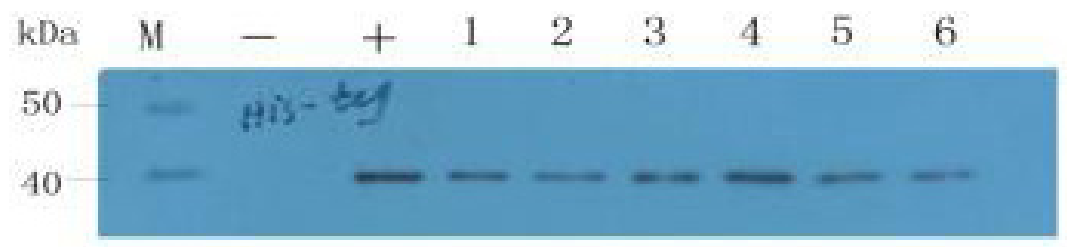

Figure 5. Western blot analysis of transgenic lettuce plants. Lane $M=$ marker, lane $-=$ negative control, lane $+=$ positive control, lanes 1-6 = transformed lettuce.

\section{In vitro biological activity assays}

Crude protein extracts from transgenic and non-transgenic lettuce were used for antimicrobial assays with B. subtilis and P. aeruginosa bacteria (Figure 6), Figures 6A and 6B 
represent the transformed sample and negative control; the inhibition zones of samples 1-3 in $B$. subtilis were smaller than those in $P$. aeruginosa, whereas the non-transgenic plants did not form an inhibition zone, which initially confirmed that the $N P-1$ gene was an expressed protein in transgenic lettuces.
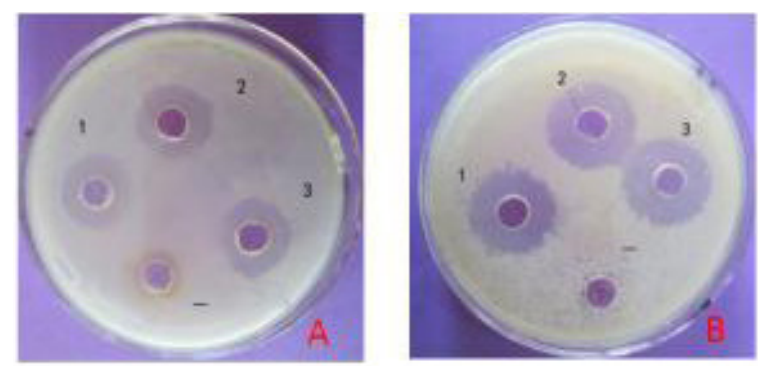

Figure 6. In vitro microbial activity against Bacillus subtilis $(\mathbf{A})$ and Pseudomonas aeruginosa $(\mathbf{B})$. The protein of transgenic lettuces $(1,2,3)$ showed antibacterial activity, whereas the control (-) had no antibacterial activity.

\section{DISCUSSION}

Since the first transgenic tobacco plant was developed in 1983, plant genetic engineering has made remarkable achievements. Lettuce has emerged as a valuable organism for transgenic plant research, and exogenous gene expression is stable and highly inherited in lettuce progenies (Song et al., 2014). However, the transfer of the rabbit defensin NP-1 gene into lettuce has not yet been reported to our knowledge. In this study, the universal method of Agrobacterium-mediated transformation was modified and used to express the rabbit defensin NP-1 gene in lettuce. Successful transgenesis could be easily influenced by in vitro plant regeneration systems (Thirukkumaran et al., 2009; Zhao et al., 2011). Therefore, the lettuce regeneration system was optimized with an approximately $70 \%$ regeneration rate of cotyledon explants. In addition, phenolic compounds are helpful to improve the conversion efficiency. Xu et al. (1988) first demonstrated that the excitation and efficient expression of the virulence (Vir) gene, which is necessary for the Ti plasmid of the Agrobacterium transfer into the host cell, was activated by AS trauma-induced molecules. Lai et al. (2006) identified 11 AS-induced proteins, which were implicated in Agrobacterium virulence. Therefore, $100 \mu \mathrm{M}$ AS was added in this experiment.

Appropriate antibiotics ensured high efficiencies of target transgenic plant screening (Wang et al., 2006). In the present experiment, the neomycin phosphotransferase (NPTII) gene, which can phosphorylate kanamycin hydroxyls, was used as a selective marker. An antibiotic sensitivity test showed that the optimal concentration for kanamycin and the bacteriostatic agent, carbenicillin, were $75 \mathrm{mg} \mathrm{L}^{-1}$ and $500 \mathrm{mg} \mathrm{L}^{-1}$, respectively. However, many kanamycinresistant plants failed to amplify target gene fragments in the PCR analysis, which suggested there were some false transformants.

The maize Ubil promoter is more effective than the CaMv35S promoter and has a low copy number of genes foreign to plants (Chen et al., 2001a; Xu et al., 2004). In this report, the rabbit defensin $(N P-1)$ gene was driven by the Ubil promoter in lettuce. As expected, PCR showed that a unique band of $130 \mathrm{bp}$ in length was amplified in transgenic plant genomes; and the Southern blot analysis showed a $2.3 \mathrm{~kb} \mathrm{NP-1}$ gene fragment from regenerated plants after

Genetics and Molecular Research 16 (1): gmr16019333 
hybridization, which is consistent with previous research (Li et al., 2004), further evidence that the NP-1 gene was transferred into the lettuce. Western blot analysis detected the presence of the NP-1 fusion protein in lettuce. The size of the target protein monomer was about 3.9 $\mathrm{kDa}$, but the target protein of six samples detected in this experiment was about $40 \mathrm{kDa}$, which demonstrated that the target protein existed in the form of a polymer in a water solution. The six histidine (His) residues added upstream in the $N P-1$ gene combined with the target protein to form a dimer or polymer (Li et al., 2004). This indicated the target gene was expressed in plants.

The antibacterial activity in vitro would be helpful in confirming the expression of foreign genes in lettuce. Results showed that the transformed plants inhibited B. subtilis and $P$. aeruginosa growth, which was consistent with the results of $N P-1$ genes introduced into poplar and Chlorella (Zhao et al, 1999; Wang et al., 2001). The NP-1 disease-resistant mechanism was combined with a virus coat protein to lose their biological activity (Chen et al., 2001b). However, only three strains showed better inhibitory effects in six positive transgenic plants, which may be owing to the following: first, the low expression of the $N P-1$ gene; there is a threshold level of transgene-derived transcripts, and disease-resistant mechanisms cannot be triggered until the threshold level in transgenic plants is reached (Fu et al., 1998); second, the genetic variation of other disease-resistant related genes during the process of transformation; and third, false positives.

In conclusion, we developed lettuce plants transformed with the $N P-1$ gene, and confirmed that the exogenous gene was quantitatively expressed in plants and showed positive bacterial inhibition. Presently, research on NP-1 is focused on its disease resistance in transgenic plants, and further research work should be performed on its medical applications.

\section{ACKNOWLEDGMENTS}

Research supported by Science Foundation of China Three Gorges University.

\section{REFERENCES}

Chen Y, Ge YQ, Li WB, Zhang LM, et al. (2001a). Advances in the research and application of mammal defensin. Prog. Biochem. Biophys. 28: 17-21.

Chen Y, Wang Y, Sun Y, Zhang L, et al. (2001b). Highly efficient expression of rabbit neutrophil peptide-1 gene in Chlorella ellipsoidea cells. Curr. Genet. 39: 365-370. http://dx.doi.org/10.1007/s002940100205

Chitrampalam P, Cox CA, Turini TA and Pryor BM (2010). Efficacy of coniothyrium minitans on lettuce drop caused by Sclerotinia minor in desert agro-ecosystem. Biol. Control 55: 92-96. http://dx.doi.org/10.1016/j. biocontrol.2010.07.003

Dias BB, Cunha WG, Morais LS, Vianna GR, et al. (2006). Expression of an oxalate decarboxylase gene from Flammulina sp. in transgenic lettuce (Lactuca sativa) plants and resistance to Sclerotinia sclerotiorum. Plant Pathol. 55: 187-193. http://dx.doi.org/10.1111/j.1365-3059.2006.01342.x

Fu RZ, Peng YF and Sun YR (1998). Expression of rabbit defensin NP-1 gene in transgenic tobacco and the study of its resistance to bacterial wilt of tobacco. Chin. Sci. Bull. 43: 1544-1550. http://dx.doi.org/10.1007/BF02883446

Li X, Wang YQ, Sa QL, Zhang LM, et al. (2004). Advance in the research of defensin gene engineering. Chin. J. Biotechnol. 23: 6-10.

Lai EM, Shih HW, Wen SR, Cheng MW, et al. (2006). Proteomic analysis of Agrobacterium tumefaciens response to the Vir gene inducer acetosyringone. Proteomics 6: 4130-4136. http://dx.doi.org/10.1002/pmic.200600254

Murashige T and Skoog F (1962). A revised medium for rapid growth and bio assays with tobacco tissue cultures. Physiol. Plant. 15: 473-497.

Rabinstein AA (2006). Treatment of cerebral edema. Neurologist 12: 59-73. http://dx.doi.org/10.1097/01. $\underline{\mathrm{nrl} .0000186810 .62736 . \mathrm{f0}}$

Genetics and Molecular Research 16 (1): gmr16019333 
Rabbit defensin NP-1 gene transfer and expression in lettuce

Song D, Han Q, Dong ZN, He ZQ, et al. (2014). Genetic transformation of lettuce (Lactuca sativa): A review. Afr. J. Biotechnol. 13: 1686-1693. http://dx.doi.org/10.5897/AJB2014.13651

Thirukkumaran G, Ntui VO, Khan RS and Mii M (2009). Thidiazuron: an efficient plant growth regulator for enhancing Agrobacterium-mediated transformation in Petunia Hybrida. Plant Cell Tissue Organ Cult. 99: 109-115. http:// dx.doi.org/10.1007/s11240-009-9581-3

Wesołowska A, Nikiforuk A, Michalska K, Kisiel W, et al. (2006). Analgesic and sedative activities of lactucin and some lactucin-like guaianolides in mice. J. Ethnopharmacol. 107: 254-258. http://dx.doi.org/10.1016/j.jep.2006.03.003

Waipara NW (2006). Isolation of white rot, Sclerotinia sclerotiorum, causing leaf necrosis on Tradescantia fluminensis in New Zealand. Australas. Plant Dis. Notes 1: 27-28. http://dx.doi.org/10.1071/DN06012

Wang L, Zhang J and Wang D (2006). Antibiotics on Agrobacterium tumefaciens antibacterial effects and the impact of tobacco leaf differentiation. Acta Tabac. Sin. 12: 32-37.

Wang YQ, Chen Y, Bai QH, Zhao SM, et al. (2001). Using transgenic Chlorella ellipsoidea as bio-reactor to produce abbit Defensin. High Technol. Lett. 11: 1-5.

Xu Y, Jia JF and Zheng GC (1988). Agrobacterium mediated efficient transformation of plant explant enhanced by phenolic compound. Chin. Sci. Bull. 22: 1745-1748.

Xu ZQ, Gong LG, Huang X, Zhang YY, et al. (2004). Transgenic maize plants with low copy number of foreign genes were produced with maize Ubi-1 promoter. Sheng Wu Gong Cheng Xue Bao 20: 120-125.

Yoichi K, Ryoi F, Keita S and Takahide S (2006). A transgenic lettuce line with resistance to both lettuce big-vein associated virus and mirafiori lettuce virus. J. Am. Soc. Hortic. Sci. 131: 760-763.

Yoichi K, Ryoi F and Yuji N (2009). Transgenic resistance to Mirafiori lettuce virus in lettuce carrying inverted repeats of the viral coat protein gene. Transgenic Res. 18: 113-120. http://dx.doi.org/10.1007/s11248-008-9200-9

Zhang LY, Zhang YY, Chen RG, Zhang JH, et al. (2010). Ectopic expression of the tomato Mi-1 gene confers resistance to Root Knot Nematodes in Lettuce (Lactuca sativa). Plant Mol. Biol. Report. 28: 204-211. http://dx.doi.org/10.1007/ s11105-009-0143-y

Zhao SM, Zu GC, Liu GQ, Huang MR, et al. (1999). Introduction of rabbit defensin NP-1 gene into poplar (P. tomentosa) by Agrobacterium-mediated transformation. Yi Chuan Xue Bao 26: 711-714.

Zhao WN, Zheng SS and Ling HQ (2011). An efficient regeneration system and Agrobacterium-mediated transformation of Chinese upland rice Cultivar Hanao297. Plant Cell Tissue Organ Cult. 106: 475-483. http://dx.doi.org/10.1007/ s11240-011-9946-2

Zhou WT, Hao MM, Liu J, Qian WJ, et al. (2011). Rabbit defensin (NP-1) genetic engineering of plant. Afr. J. Biotechnol. 10: 9218-9224.

Genetics and Molecular Research 16 (1): gmr16019333 